\title{
Design of Two Channel Infusion Pump Analyzer Using Photo Diode Detector
}

\author{
Syaifudin ,Muhammad Ridha Mak'ruf, Sari Luthfiyah, Sumber \\ Department of Electromedical Engineering Poltekkes Kemenkes, Surabaya \\ Jl. Pucang Jajar Timur No. 10, Surabaya, 60245, Indonesia
}

\begin{abstract}
Article Info Abstract
Article History:

Received: April 5, 2021

Revision: April 15,2021

Accepted: May 10, 2021

\section{Keywords:}

Calibration

Flow Rate

Microcontroller

In the medical world, patient safety is a top priority. The large number of workloads and the frequency of using the devices in the long run will affect the accuracy and accuracy of the tool. If the flow rate and volume of the syringe pump or infusion pump given to the patient are not controlled (overdose or the fluid flow rate is too high) it can cause hypertension, heart failure or pulmonary edema. Therefore, it is necessary to have a calibration, which is an application activity to determine the correctness of the designation of the measuring instrument or measuring material. The purpose of this research is to make a two channel infusion device analyzer using a photodiode sensor. The contribution of this research is that the system can display three calibration results in one measurement at the same setting and can calibrate 2 tools simultaneously. The design of the module is in the form of an infrared photodiode sensor for reading the flowrate value. This study uses an infrared photodiode sensor for channels 1 and 2 installed in the chamber. This study uses a flow rate formula that is applied to the water level system to obtain 3 calibration results. Infrared photodiode sensor will detect the presence of water flowing in the chamber from an infusion or syringe pump. Then the sensor output will be processed by STM32 and 3 calibration results will be displayed on the $20 \times 4$ LCD. This tool has an average error value on channel 1 of $3.50 \%$ and on channel 2 of $3.39 \%$. It can be concluded that the whole system can work well, the placement and distance between the infrared photodiodes also affects the sensor readings.
\end{abstract}

\author{
Corresponding Autor: \\ syaifudin@poltekkesdepkes-sby.ac.id \\ Department of Electromedical Engineering \\ Poltekkes Kemenkes, Surabaya
}

This work isan open-access article and licensed under a Creative Commons Attribution-ShareAlike 4.0 International License( $\underline{\text { CC BY-SA 4.0) }}$.

\section{INTRODUCTION}

In the medical world, offering intravenous fluids is very useful to support and accelerate the recovery of patients who are currently healing or in critical conditions. Intravenous infusion of fluids (infusion of intravenous fluids) is to give a certain amount of fluid into the body, through a needle, into a vein (vein) to treat dehydration due to a disease or after excessive activity with certain antibiotics or drugs [1]. A tool that functions for intravenous fluid infusion or commonly called an infusion pump or syringe pump, given the importance of providing this fluid, the accuracy of the fluid flow rate must be considered. The use of an infusion pump or syringe pump in the long term causes changes in accuracy, either flow rate or otherwise, therefore a calibration process is required. Calibration is an activity of comparing measuring instruments with measuring instruments that have high accuracy. The infusion pump and syringe pump include tools that must be calibrated, the infusion pump or syringe pump calibration process takes a relatively long time. Therefore, this study aims to design a two-channel infusion pump calibration tool that can be used to calibrate an infusion pump or a syringe pump simultaneously. The FDA Safety Communication states that drug-accurate fluids should be carefully monitored [4]. Jingzhi observed that giving intravenous fluids at a low flow requires infusion pump equipment with high accuracy [2]. Anne C examines the impact of the flow of intravenous fluids given to patients, it turns out to be very influential [9]. Hugo Bissig language in his research Microflow and nanoflow calibration is very important in several applications such as liquid chro matography, process technology (minimized), and special health care applications [10]. Nuntachai Thongpance has conducted research with the design of the infusion pump calibrator with good results. $\mathrm{N}$ Thongpance made an infusion

\section{Accredited by Ministry of Research and Technology /National Research and Innovation Agency}

Decree No: 200/M/KPT/2020

Journal homepage: http://ijeeemi.poltekkesdepkes-sby.ac.id/index.php/ijeeemi 
pump calibrator using a load sensor to measure the flow rate[8]. In the research conducted by E Batista, it was found that the calibration using the wave method and the flow method was the most appropriate method [5]. Jingzhi research requires a calibration tool with good accuracy, a good micro drop method is used for low flow rates [6]. Elsa Batista's research, a calibration method with a flow rate that does not have low uncertainty or high accuracy [7]. The Nuntachai Thongpance study used a load sensor to check the flow rate [8].

The studies that have been carried out explain that the infusion flow rate greatly impacts the patient so that a device with high accuracy is needed. Calibration using the gravity method is strongly influenced by other factors so that it needs to be conditioned. Existing research using either the gravity method or flow rate uses only 1 channel.

To solve the existing problem, in this study, the authors used 3 infrared sensors and photodiodes to determine the flow rate and made them into 2 channels. By using 3 sensors it is expected to be able to determine the flow rate accurately.

\section{MATERIALS AND METHODS}

\section{A. Research Design}

The results of the infusion device analyzer design in this study are used to calibrate the Unit Under Test (UUT) using 2 syringe pumps that have been calibrated by a legal calibration body. Syringe pump 1 uses the Terumo TE-331 brand and Syringe pump 2 uses the Terumo TE-331 brand by using the setting; 10, 50 and $100 \mathrm{ml} /$ hour.

Research using volume tube (chamber) is used to accommodate the water that comes out of the Syringe Pump. 3 infrared photodiode sensors function as detectors of the liquid in the instrument chamber. The infrared photodiode sensor output is then entered and processed to the ADC pin of the microcontroller. STM32 as a controller and controller. The microcontroller output is a display on the $20 \mathrm{x} 4$ Character LCD.

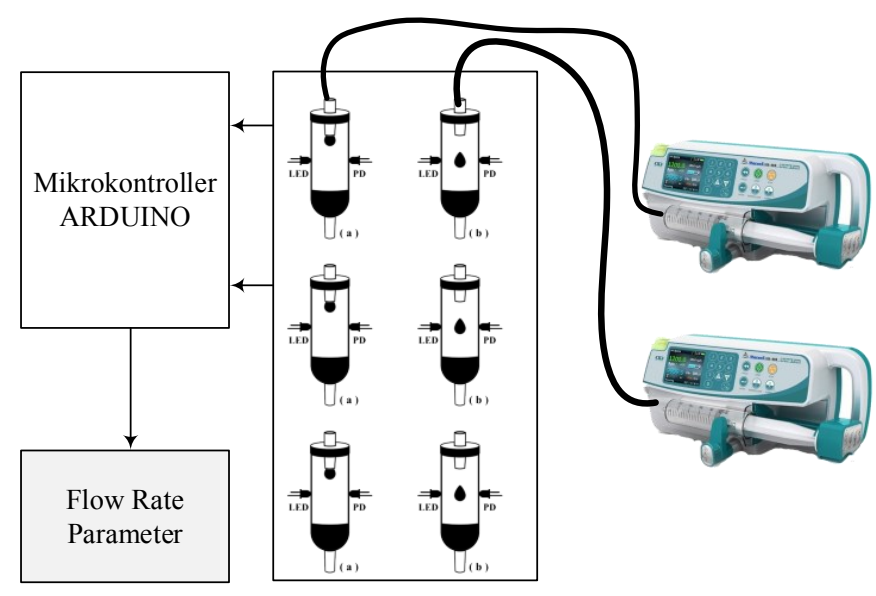

Fig. 1. Dual Channel Infusion Device Analyzer
The output voltage from the infrared photodiode will go to the input pin (-) of the comparator to be compared with the reference voltage that comes from dividing the voltage that goes to the input pin $(+)$.

The infared photodiode sensor has 2 conditions, namely when the sensor is not blocked by water and when the sensor is blocked by water. If the sensor voltage is greater than the reference voltage, the output output is the sensor voltage, which means that the sensor is not blocked by water. However, if the reference voltage is greater than the sensor voltage, the output output is the reference voltage, which means that the sensor is blocked by water. The output on the comparator will enter the microcontroller to be processed whether the sensor detects that the water has or has not been reached on the specified sensor.

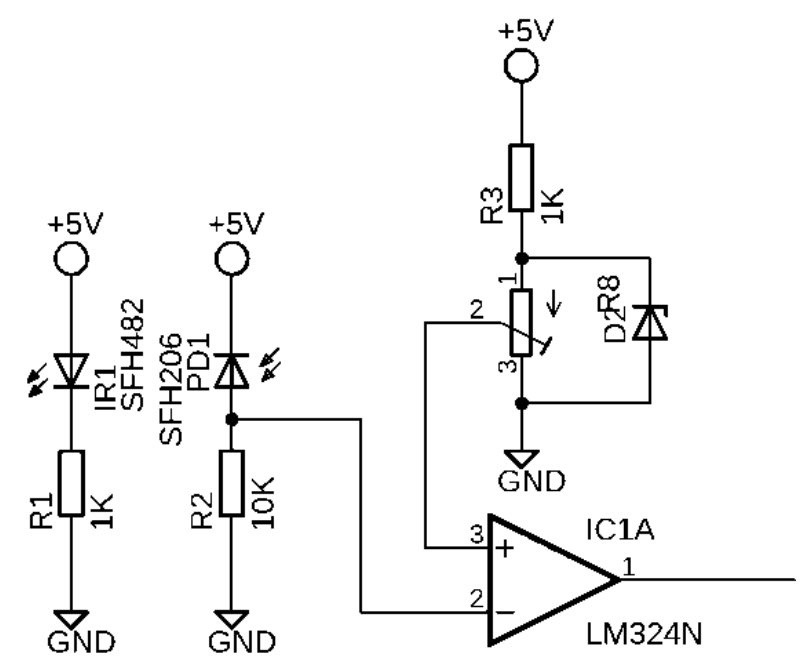

Fig. 2. Electronic Connection

\begin{tabular}{|l|l|}
\hline \multicolumn{2}{|c|}{ Algorithm } \\
\hline 1 & BEGIN \\
2 & Initialize LCD \\
3 & Input(settingdrop) \\
4 & IF Pin3 = Low THEN \\
5 & Timerbegin \\
6 & Flowrate = Vol/Timer \\
7 & BEGIN \\
8 & Display(flowrate) \\
9 & Save(Flowrate) \\
& END \\
& END. \\
\hline
\end{tabular}

\section{B. Experiment}

In this study, after the design was finished, the Syringe Pump output test was carried out in the form of flow (flow velocity) with a setting of 10.50 and $100 \mathrm{ml} /$ hour. Data retrieval was repeated 3 times for setting $10 \mathrm{ml} /$ hour and 6 times for setting 50 and $100 \mathrm{ml} /$ hour.

\section{Accredited by Ministry of Research and Technology /National Research and Innovation Agency} Decree No: 200/M/KPT/2020 
Indonesian Journal of Electronics, Electromedical, and Medical Informatics (IJEEEMI)

Vol. 3, No. 2, May 2021, pp. 65-69

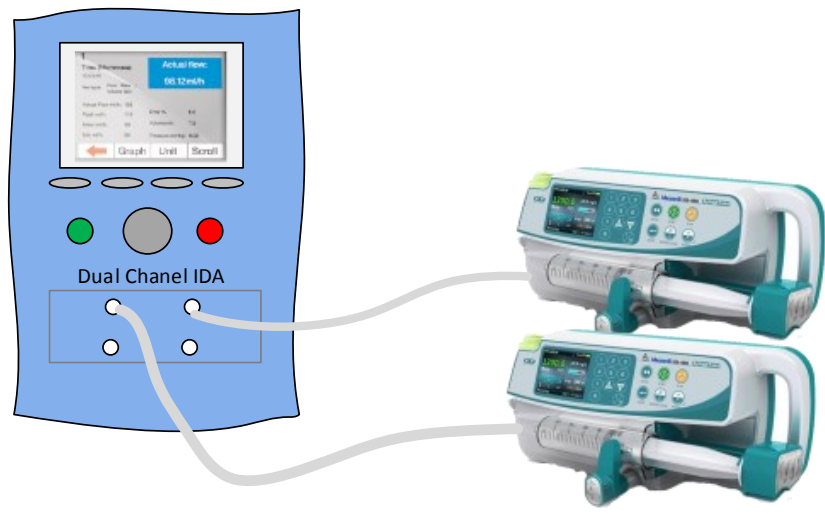

Fig. 3. Experiment in measurement process

\section{RESULTS}

Infrared photodiode sensor detects the presence or absence of liquid in the volume tube (space). Based on this circuit, if the sensor is blocked by water, the greater the resistance received by the photodiode, the greater the voltage and current sent to the microcontroller ADC pin. If the sensor is not blocked by water, the smaller the resistance it receives from the photodiode, the smaller the voltage and current transmitted to the ADC pin of the microcontroller.

After the photodiode sensor is blocked by water, the sensor output in the form of a voltage will enter the ADC pin of the microcontroller. The program on the microcontroller will calculate the time between one sensor and another when the sensor detects a liquid, this time will be converted into water flow rate. In general, this tool runs according to the program. To test the accuracy of this tool, a trial is carried out using two syringe pump ( UUT-1 and UUT-2), The result calibration UUT1 and UUT-2 from calibrated by a legal calibration

TABLE I. RESULT CALIBRATION UUT-1

\begin{tabular}{ccc}
\hline Flow Rate $(\mathrm{ml})$ & \% Error $(\mathrm{ml})$ & $\mathrm{U}$ \\
\hline 10 & -1.5 & 2.7 \\
\hline 50 & -6.7 & 1.6 \\
\hline 100 & -3 & 0.1 \\
\hline
\end{tabular}

TABLE II. RESUlt CALIBRATION UUT-2

\begin{tabular}{ccc}
\hline Flow Rate $(\mathrm{ml})$ & \% Error $(\mathrm{ml})$ & $\mathrm{U}$ \\
\hline 10 & -5 & 0.25 \\
\hline 50 & -3.8 & 0.25 \\
\hline 100 & -1.8 & 0.9 \\
\hline
\end{tabular}

The results are as follows :
TABLE III. MEASUREMENT UUT -1 ON SETTING 10 ML/HOUR

\begin{tabular}{lcc}
\hline & Channel $-1(\mathrm{ml})$ & Channel-2 $(\mathrm{ml})$ \\
\hline Flow rate & 10.15 & 9.66 \\
& 9.98 & 9.92 \\
& 9.14 & 9.53 \\
\hline \% Error & 2.43 & 2.97 \\
\hline $\mathrm{U}$ & 0.31 & 0.11 \\
\hline
\end{tabular}

TABLE IV. MEASUREMENT UUT -2 ON SETTING 10 ML/HOUR

\begin{tabular}{lcc}
\hline & Channel $-1(\mathrm{ml})$ & Channel-2 $(\mathrm{ml})$ \\
\hline Flow rate & 9.68 & 9.88 \\
& 10.34 & 9.97 \\
& 9.61 & 10.07 \\
\hline \% Error & 1.23 & 0.27 \\
\hline $\mathrm{U}$ & 0.23 & 0.05 \\
\hline
\end{tabular}

TABLE V. MEASUREMENT UUT-1 ON SETTING 50 ML/HOUR

\begin{tabular}{lcc}
\hline & Channel $-1(\mathrm{ml})$ & Channel-2 $(\mathrm{ml})$ \\
\hline Flow Rate & 50.41 & 51.09 \\
& 50.91 & 51.1 \\
& 51 & 50.97 \\
& 50.79 & 51.32 \\
& 52.34 & 51.1 \\
& 50.84 & 51.19 \\
\hline U Error & -2.1 & -2.26 \\
\hline
\end{tabular}

TABLE VI. MEASUREMENT UUT-2 ON SETTING 50 ML/HOUR

\begin{tabular}{ccc}
\hline & Channel $-1(\mathrm{ml})$ & Channel-2 $(\mathrm{ml})$ \\
\hline Flow Rate & 49.82 & 59.81 \\
& 53.48 & 50.88 \\
& 48.26 & 50.03 \\
& 50.85 & 50.86 \\
& 52.99 & 50.54 \\
& 48.87 & 51.31 \\
\hline \% Error & -1.42 & -1.48 \\
\hline U & 0.88 & 0.17
\end{tabular}


Indonesian Journal of Electronics, Electromedical, and Medical Informatics (IJEEEMI)

Vol. 3, No. 2, May 2021, pp. 65-69

DOI:10. 35882/ijeeemi.v3i2.5

TABLE VII. MEASUREMENT UUT-1 ON SETTING 100 ML/HOUR

\begin{tabular}{lcc}
\hline & Channel $-1(\mathrm{ml})$ & Channel-2 $(\mathrm{ml})$ \\
\hline Flow Rate & 102 & 100.2 \\
& 99.67 & 98.32 \\
& 101.3 & 103.8 \\
& 99.86 & 103.3 \\
& 102.8 & 101.3 \\
& 98.57 & 98.85 \\
\hline U Error & -0.7 & -0.96 \\
\hline
\end{tabular}

TABLE VIII. MEASUREMENT UUT-2 ON SETTING 100 ML/HOUR

\begin{tabular}{lcc}
\hline & Channel $-1(\mathrm{ml})$ & Channel-2 $(\mathrm{ml})$ \\
\hline Flow Rate & 100.3 & 100.8 \\
& 98.82 & 99.15 \\
& 98.57 & 98.28 \\
& 101.8 & 101.9 \\
& 103.9 & 100 \\
& 98.26 & 99.94 \\
\hline \% Error & -0.26 & -0.01 \\
\hline U & 0.9 & 0.51 \\
\hline
\end{tabular}

\section{DISCUSION}

Based on the results of measurements that have been made, it can be seen that the level of accuracy and precision of this tool is good. The measurement results obtained at the $10 \mathrm{~mL} /$ hour setting compared to comparator 1 give an indication that the measurement value is below the actual price (comparison average) and the resulting error is $2.43 \%$ on channel 1 and an error of $2.97 \%$ in channel 2 . While the comparison tool shows an error of $-1.5 \%$. The measurement results obtained at the 10 $\mathrm{mL} /$ hour setting compared to comparator 2 give an indication that the measurement value is below the actual price (comparison average) and the resulting error is $1.23 \%$ on channel 1 and an error of $0.27 \%$ in channel 2 . Meanwhile, the comparison tool shows an error of $-5 \%$.

TABLE IX. T-TEST EQUAL VARIANCES TO SEE IF THERE IS A DIFFERENCE BETWEEN CHANNEL 1 AND CHANNEL 2 FOR 10ML/HOUR

\begin{tabular}{lccccc}
\multicolumn{2}{l}{ T TEST: Equal Variances } & \multicolumn{2}{c}{ Alpha } & 0.05 \\
\hline \hline & std err & t-stat & df & p-value & t-crit \\
\hline One Tail & 0.46306 & 0.356325 & 2 & 0.377838 & 2.919986 \\
Two Tail & 0.46306 & 0.356325 & 2 & 0.755676 & 4.302653 \\
\hline
\end{tabular}

From the test results, there is no difference between Channel 1 and Channel 2 for $10 \mathrm{ml} /$ Hour. The measurement results obtained at the $50 \mathrm{~mL}$ / hour setting compared to comparator 1 give an indication that the measurement value is below the actual price (comparison average) and the resulting error is $2.10 \%$ on channel 1 and an error of $-2.26 \%$ on channel 2 . While the comparison tool shows an error of $-6.7 \%$. The measurement results obtained at the $50 \mathrm{~mL} /$ hour setting compared to comparator 2 give an indication that the measurement value is below the actual price (comparison average) and the resulting error is $-1.42 \%$ on channel 1 and an error of $-1.48 \%$ on channel 2. While the comparison tool shows an error of $-3.8 \%$.

TABLE X. T-TEST EQUAL VARIANCES TO SEE IF THERE IS A DIFFERENCE BETWEEN CHANNEL 1 AND CHANNEL 2 FOR 50 ML/HOUR

\begin{tabular}{cccccc}
\multicolumn{2}{c}{ T TEST: Equal Variances } & \multicolumn{2}{c}{ Alpha } & 0.05 \\
\hline \hline & std err & $t$-stat & $d f$ & $p$-value & $t$-crit \\
\hline One Tail & 0.368409 & 0.122147 & 2 & 0.456975 & 2.919986 \\
Two Tail & 0.368409 & 0.122147 & 2 & 0.913949 & 4.302653 \\
\hline
\end{tabular}

From the test results, there is no difference between Channel 1 and Channel 2 for $50 \mathrm{ml} /$ Hour. The measurement results obtained at the $100 \mathrm{~mL}$ / hour setting compared to comparator 1 give an indication that the measurement value is below the actual price (comparison average) and the resulting error is $0.70 \%$ on channel 1 and the error is $-0.96 \%$ on channel 2 . While the comparison tool shows an error of $-3 \%$. The measurement results obtained at the $100 \mathrm{~mL} /$ hour setting compared to comparator 2 give an indication that the measurement value is below the actual price (comparison average) and the resulting error is $-0.26 \%$ on channel 1 and an error of $-0.01 \%$ on channel 2. While the comparison tool shows an error of $-1.8 \%$.

TABLE XI. T-TEST EQUAL VARIANCES TO SEE IF THERE IS A DIFFERENCE BETWEEN CHANNEL 1 AND CHANNEL 2 FOR 50 ML/HOUR

\begin{tabular}{lccccc}
\multicolumn{2}{c}{ T TEST: Equal Variances } & & & Alpha & 0.05 \\
\hline \hline & std err & t-stat & df & p-value & t-crit \\
\hline One Tail & 1.259729 & 0.33023 & 8 & 0.374854 & 1.859548 \\
Two Tail & 1.259729 & 0.33023 & 8 & 0.749708 & 2.306004 \\
\hline
\end{tabular}

From the test results, there is no difference between Channel 1 and Channel 2 for $100 \mathrm{ml} /$ Hour.

\section{Conclusion}

The purpose of this study is to design a dual infusion pump analyzer based on microcontroller. After making the infusion device analyzer using STM32 as a microcontroller, the infrared photodiode sensor works well, it can display the results on the $20 \mathrm{x} 4$ character LCD in the form of numbers and letters with $3 \mathrm{x}$ the measurement results, channels 1 and 2 can be used

\section{Accredited by Ministry of Research and Technology /National Research and Innovation Agency Decree No: 200/M/KPT/2020}


simultaneously on the same parameters. The measurement results on the flowrate channel 1 parameter obtained a fairly high uncertainty figure compared to the flowrate channel 2 parameter. The placement of the infrared photodiode sensor and the distance between the infrared photodiode sensors also affects this measurement which results in channel 1 being higher. Air bubbles greatly affect the sensor readings. After testing and measuring, the average error value on channel 1 is $3.50 \%$ and channel 2 is $3.39 \%$. These results are obtained from the difference between the error value and the comparison. It can be concluded that this tool has met the standards. The results of the infrared photodiode sensor readings on channel 1 and channel 2 show close results. The development of this research can be done by improving the mechanics and improving the display of the module so that it is like a standard tool by displaying graphs on the display because correct, accurate and real time graph depiction can help users to analyze the calibration results obtained. It uses a better sensor than Photodioda infrared for flowrate parameters. It is advisable to use an automatic drain like a standard tool. Adds 4 channels like a standard tool and features a graphic display. Added calibration certificate.

\section{REFERENCES}

[1] S. Riskitasari and et.al, "Sistem Monitoring Level dan Tetesan Cairan Intravena Pada Pasien Rawat Inap Menggunakan Komunikasi NRF24L01," Pros. SNATIF, vol. 4, pp. 17-24, 2017.

[2] Jingzhi. Evaluation of Clinical Infusion Pump Performance Through Downstream Microdrop Monitoring: A Preliminary Study, 978-1-7281-19908/20-IEEE, 2020

[3] B. G. I. INC, Infusion_Pump_Rental. ST. CHARLES, 2012.

[4] Syringe Pump Problems with Fluid Flow Continuity at Low Infusion Rates Can Result in Serious Clinical Consequences: FDA Safety Communication, 2016

[5] E Batista at al "Calibration of Infusion Pumps Analyser", in 2018, XXII World Congress of the International Measurement Confederation

[6] Jingzhi An at al "Evaluation of Clinical Infusion Pump Performance Through Downstream Microdrop Monitoring: A Preliminary Study" 978-1-7281-19908/20/\$31.00 C2020 IEEE

[7] E Batista "Comparison of infusion pumps calibration methods", 2017, Comparison of infusion pumps calibration methods - IOPscience

[8] Nuntachai Thongpance "The Design and Construction of Infusion Pump Calibrator", 2012, The 2012 Biomedical Engineering International Conference (BMEiCON-2012)

[9] Anne C, A literature review on flow-rate variability in neonatal IV therapy, Blackwell Publishing Ltd Pediatric Anesthesia 2012

[10] Hugo Bissig, Primary standards for measuring flow rates from $100 \mathrm{nl} / \mathrm{min}$ to $1 \mathrm{ml} / \mathrm{min}$ - gravimetric principle, Biomed. Eng.-Biomed. Tech. 2015; 60(4): 301-316

Accredited by Ministry of Research and Technology /National Research and Innovation Agency 